
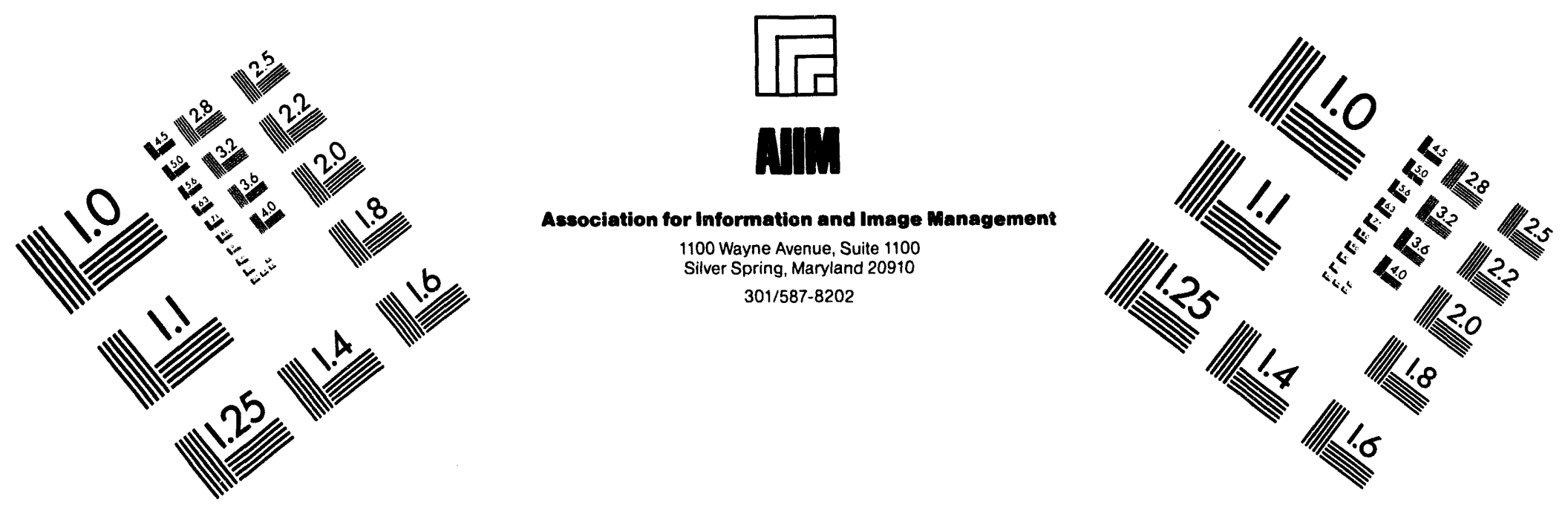

Centimeter

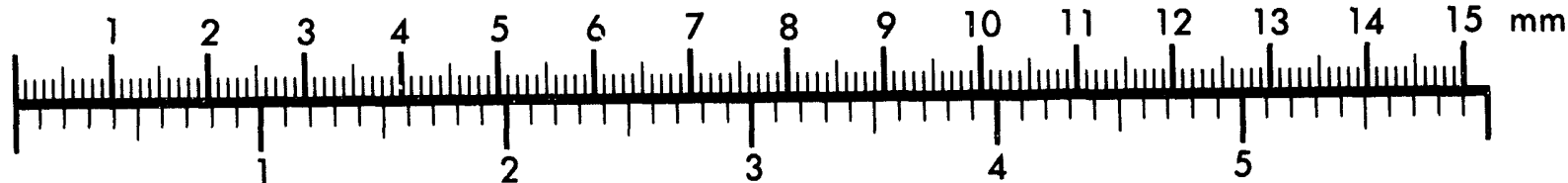
Inches
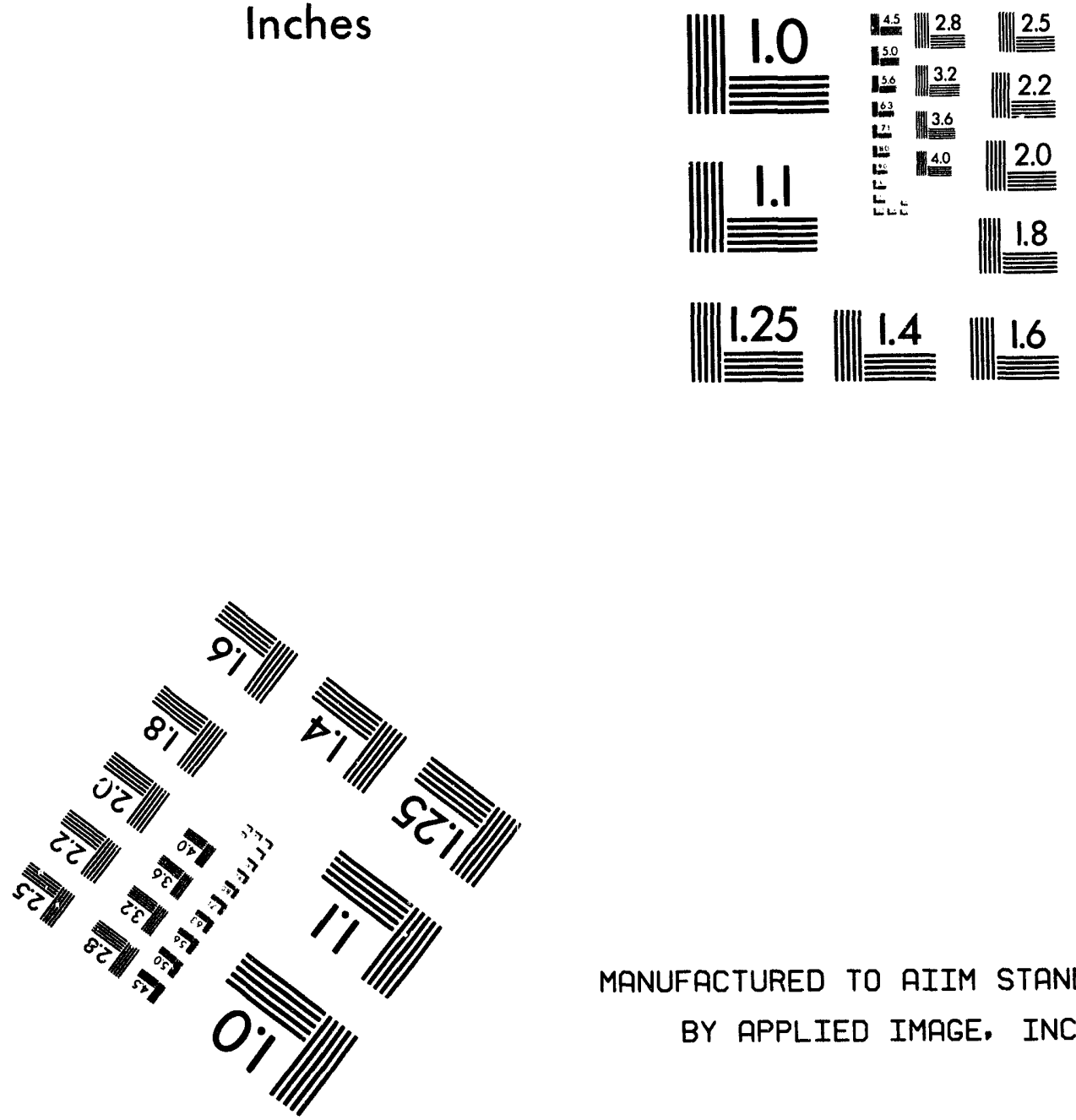

MANUFACTURED TO AIIM STANDARDS

BY APPLIED IMAGE. INC.

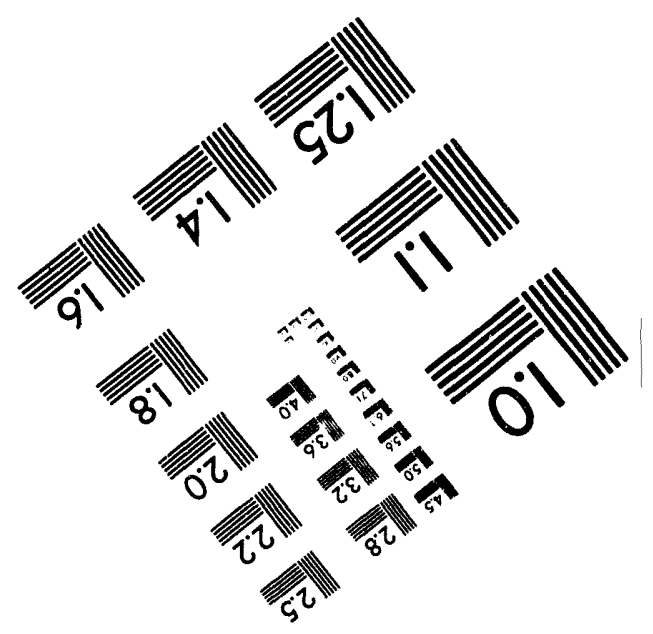



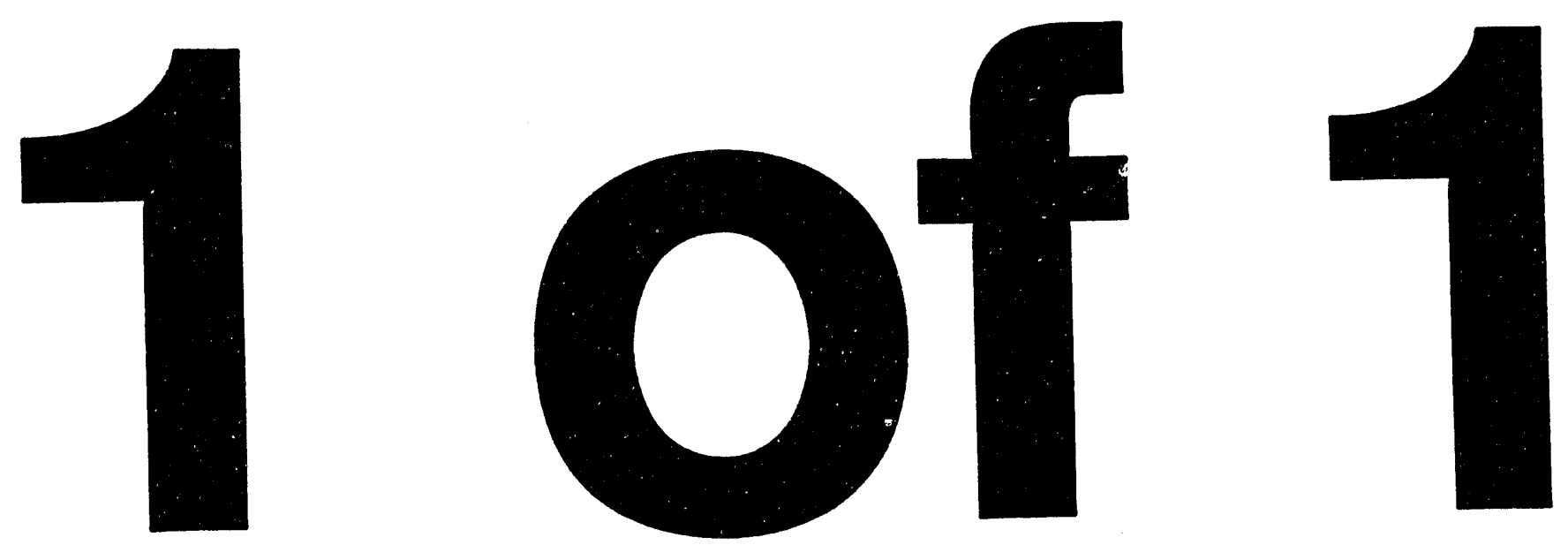


\title{
The Organic Chemistry of Conducting Polymers
}

\author{
Annual Technical Report
}

February 1, 1993 to May 31, 1994

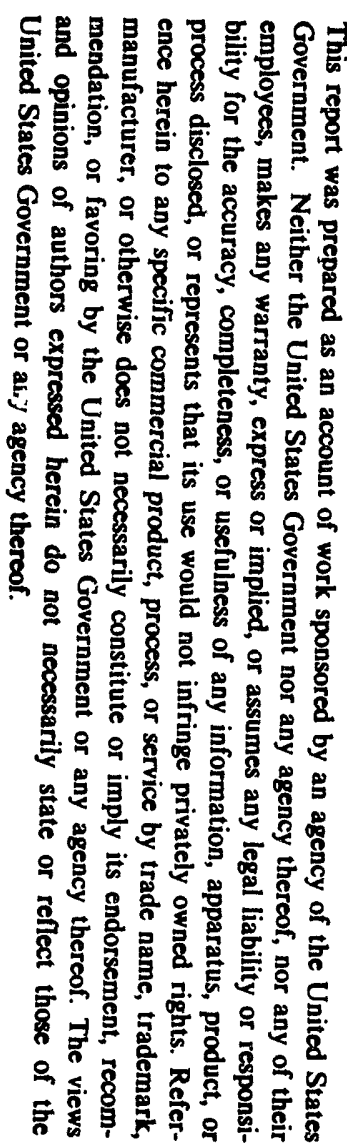

\author{
Submitted by: \\ Laren M. Tolbert \\ School of Chemistry and Biochemistry \\ Georgia Institute of Technology \\ Atlanta, GA 30332-0400
}

August 19, 1994

Prepared for:

Division of Materials Science

Office of Basic Energy Sciences

U. S. Department of Energy

Under grant number DE-FG05-91ER45194

(successor to DE-FG05-85ER45194)

\section{MSTER}




\section{Solitons in a box.}

Polyacetylene represents the prototypical example of a Peierls distortion in an unconjugated material which, in the absence of such distortion, would have a zero band-gap. According to the Su, Schrieffer, and Heeger (SSH) theory, doping of polyacetylene introduces a carrier at midgap, a soliton, ${ }^{1}$ which migrates down the chain, interconverting $R$ and $L$ polyacetylene (see Figure 1$).^{2}$ In the case of $n$-doped polyacetylene, this soliton is topologically equivalent to an odd-alternant hydrocarbon anion, a subject of historic interest in our laboratories. In order to establish the structure of the soliton, we have synthesized "solitons in a box", ${ }^{3}$ i. e., molecules of known conjugation lengths, specifically, $\alpha, \omega-$ diphenylpolyenyl anions of general formula $\mathrm{Ph}(\mathrm{CH})_{\mathrm{n}} \mathrm{Ph}^{-}, \mathrm{n}=1-17,(\mathrm{DP1}, \mathrm{DP3}, \mathrm{DP5}, \ldots$ DP17).

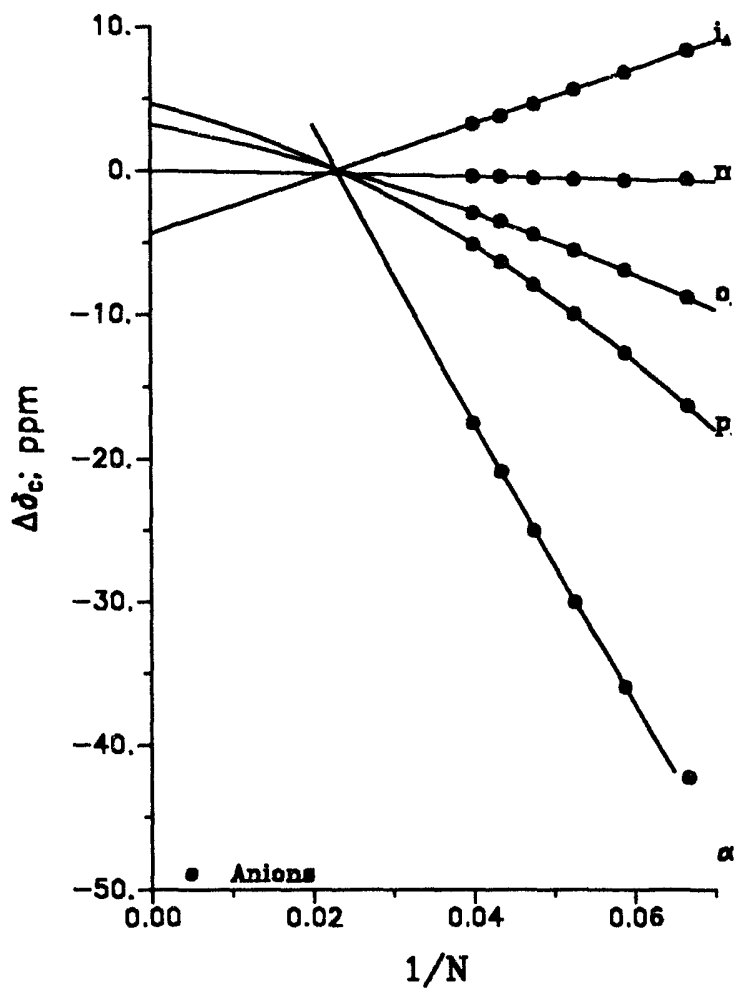

Figure 2. Convergence of ${ }^{13} \mathrm{C}$ chemical

Figure 2. Convergence of ${ }^{13} \mathrm{C}$ cher
shift differences vs. $1 / \mathrm{N}$.

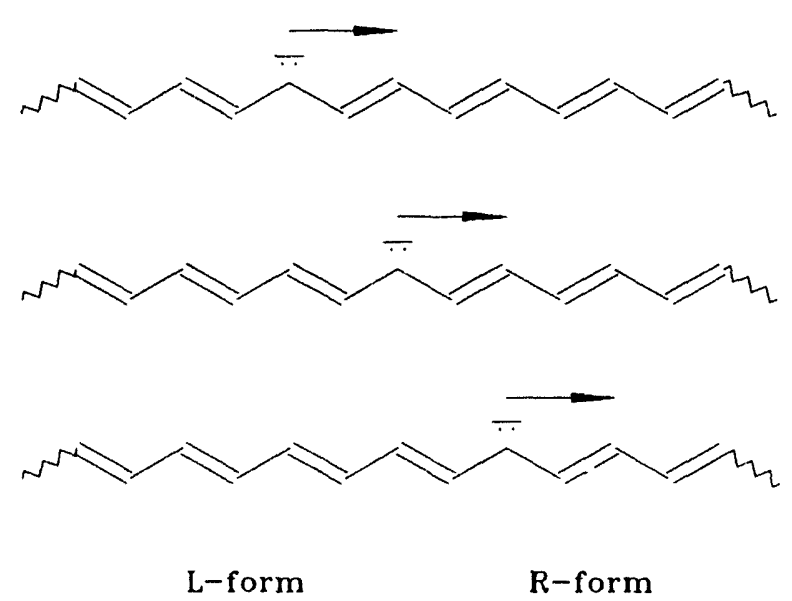

Figure 1. Coupled soliton modes in $n$ doped polyacetylene.
Although the correlation between conjugation length and energy gap has been studied for a number of neutral olefins and radical anions and cations, ${ }^{4}$ no such study existed for soliton model compounds. The use of species DPN with discrete conjugation lengths enabled us to confirm the optical properties of the soliton by extrapolation to the nearly infinite chain. ${ }^{5}$ More spectacular were our results using the ${ }^{13} \mathrm{C}$ nuclear magnetic resonance chemical shifts. ${ }^{6} \mathrm{By}$ plotting the chemical shift differences $\left(\Delta \delta_{c}\right)$ between anionic and neutral diphenylpolyenes against $1 / \mathrm{N}$, where $\mathrm{N}$ is the total carbon number, we obtained a vanishing point for the terminal phenyl rings representing the confinement width for the soliton. After correction for the two benzyl groups, the extrapolated soliton width is $31-33$, equivalent to that predicted by theory. 
2. Cyanines as molecular switches: beyond the cyanine limit.

The presence of band gaps (the Peierls distortion) in polyacetylene represents one end of the bond-alternation limit in which full bond alternation has been achieved. We have also been investigating materials which represent the other limit, the "cyanine limit", so-called because the most important examples are provided by the symmetrical cyanines. Cyanines exhibit no significant bond alternation, a consequence of the two equivalent resonance forms in the usual valence bond model (see Figure 3). Several crystal structures of cyanines of various types confirm the lack of bond-alternation in cyanines, ${ }^{8}$ and thus the correlation with $1 / \mathrm{N}_{\text {eff }}$ provides a zero intercept. This observation raises a question: what is the effect of extending cyanine width beyond those currently available? The closing of the gap at<smiles>[2H][n+]1ccc(/C=C/C=C/C=C/c2cc[n+]([Pb])cc2)cc1</smiles><smiles>[Y]=[W]=N/C=C/C=C/C=C/c1cc[n+]([2H])cc1</smiles><smiles></smiles>

Figure 3. Charge migration in dipyridylpolyenyl anions.

infinite length, which would make a long cyanine a true metal, is unstable relative to a Peierls distortion. What is the point at which the Peierls distortion would take effect, that is, when would the cyanine limit fail? A partial answer is provided by $\mathrm{Kuhn}^{9 \mathrm{a}}$, who, based upon a free electron model, determined that simple cyanines with 30 carbon atoms should exhibit asymmetric ground states. Recently, Hush and coworkers have confirmed this prediction at a higher calculational level..$^{\text {pb-d }}$

In order to maintain a systematic approach to the investigation of solitonic behavior in molecules, we have investigated molecules analogous to the diphenylpolyenyl anions DPN in which the para carbon of each phenyl was replaced by nitrogen, i. e., phenyl became 4-pyridinium (acronym DPyN). Although the resulting species were isoelectronic with the parent DPN, we expected that electrostatic interactions
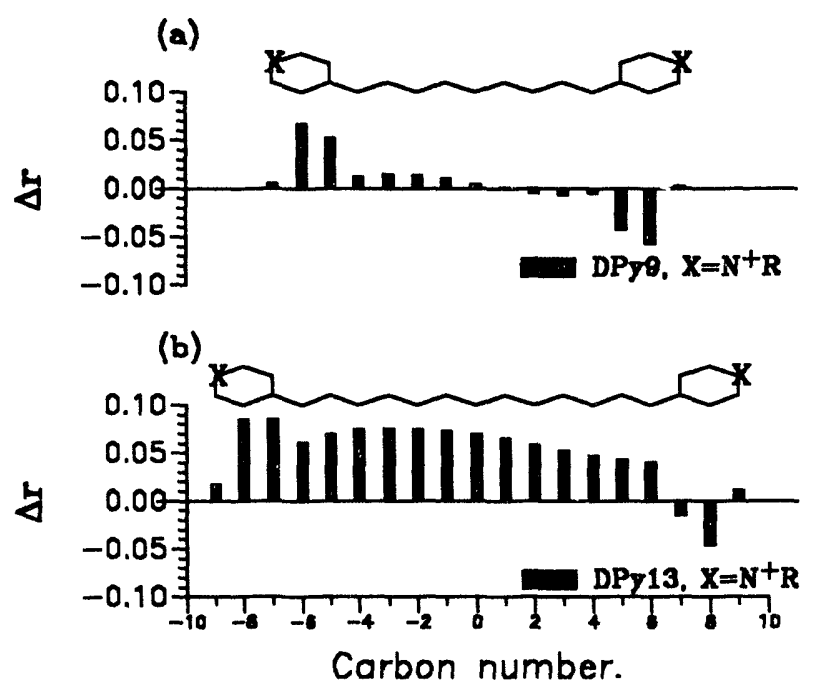

Figure 4. Bond alternation in DPy9 and DPy13: (a) DP9; (b) DPy13 fully relaxed. 
would cause the negative charge localized in the center of such a moiety to migrate to one end or the other to annihilate the positive charge. Each resulting structure corresponded to one of two equivalent resonance forms of a cyanine dye (see Figure 3). Again, at sufficient length the finite soliton width required that the two forms no longer be equivalent due to bond alternation induced by Peierls distortion. Thus the electron density should localize at one end or the other of the polyene, but the ends could not communicate except through solitonic motion. Preliminary calculations at the AM1 level predicted

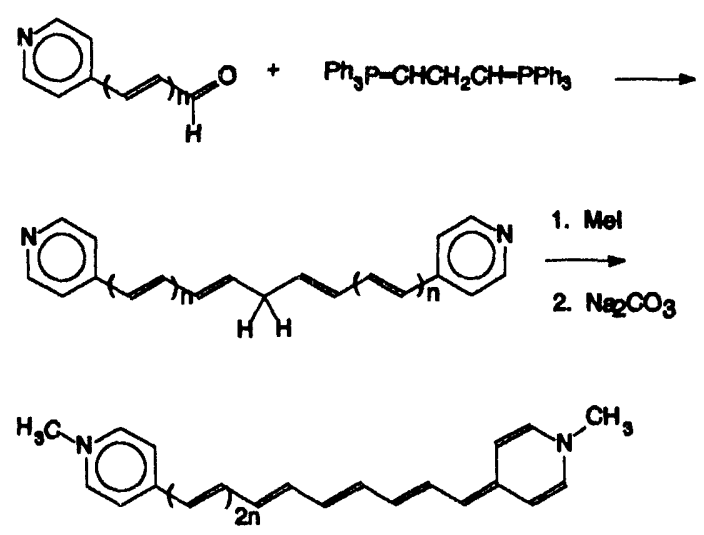

Figure 5. Synthesis of cyanines $\mathbf{D P y N}, \mathbf{N}=$ $5,9,13$. that formation of the asymmetric ground state should occur as early as 13 carbon centers. ${ }^{10}$ This phenomenon can be seen most readily by an examination of the bond alternation as a function of chain length. The dipyridylnonatetraenyl cation (DPy9) has a symmetric ground state, with minimal bond alternation in the vicinity of the chain center (see Figure $4 \mathrm{a}$, in which the difference in adjacent bond lengths, $\Delta r$, is plotted versus the position of the atom). In contrast, for the dipyridyltridecahexaenyl cation DPy13, $C_{2 v}$ symmetry was unstable relative to a Peierls distortion. A lifting of the symmetry to produce the asymmetric ground state shown in Figure $4 \mathrm{~b}$. Thus DPy9 clearly exhibits $C_{2 v}$ symmetry corresponding to the classical resonance picture of cyanines, while DPy13 does not.

Syntheses of cyanines of type DPN, i. e., DPy1, DPy3, DPy5, DPy9, and DPy13 were carried out. DPy1 and DPy3 were synthesized following literature procedures. The remaining cyanines were synthesized using conventional Wittig methodology (see Figure 5). The cyanines were generated by deprotonation of the intermediate bis(pyridinium)polyenes, and produced colors ranging from deep red to green to blue. The larger dyes were stable in solution, but underwent rapid reaction when exposed to oxygen.

When the spectroscopic energy gaps were plotted vs. $\left(\mathrm{N}_{\mathrm{eff}}\right)^{-1}$, where $\mathrm{N}_{\text {eff }}$ is defined as the number of polyene atoms plus 4.5 per phenyl, a linear relationship was obtained with a zero intercept for dyes DPy1 through DPy9. In contrast, DPy13

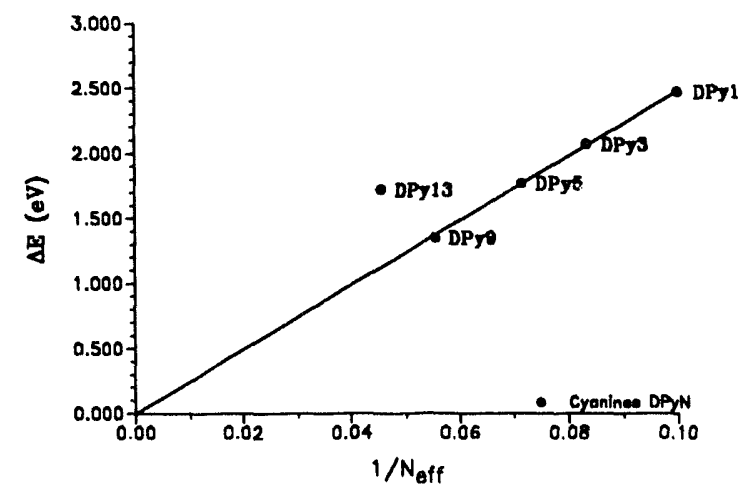

Figure 6. Energy gap vs. $\left(\mathrm{N}_{\mathrm{eff}}\right)^{-1}$ for cyanines DPy1 - DPy13. 
exhibited a remarkable hypsochromic shift (see Figure 7). Moreover, DPy13 exhibited a remarkable negative solvatochromicity relative to DPY9 and DPy5 (see Figure 7), indicating that DPy13 was considerably polarized relative to DPy9, a result again consistent with bond localization. Finally, DPy13 exhibited infrared bands indicating the onset of polarization in the double bonds. Although more definitive studies on the structure of DPy13 are in progress, these preliminary results indicated that the onset of the Peierls distortion may take place at a much shorter chain length than previously

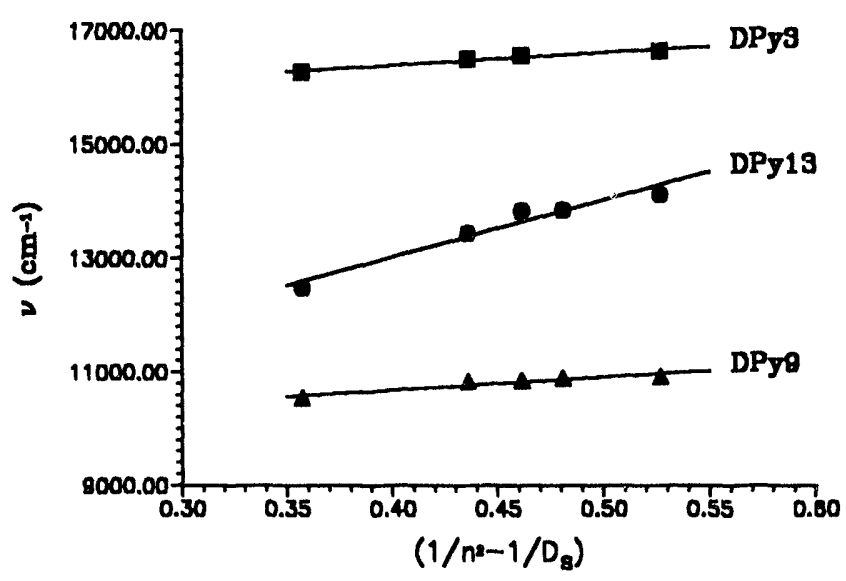

Figure 7. Increase in solvatochromic shift for DPy13. anticipated.

\section{Low Band-gap Heteropolymers.}

Although our interests in conductive polymers have been of a fundamental nature, examining details of charge-propagation mechanisms through the use of model compounds, we have also been interested in new materials with greater stability and processability than is represented by doped-polyacetylene. Efforts towards these materials have concentrated largely on heteropolymers such as polythiophene or polypyrrole and have employed a number of strategies. One approach has concentrated on reducing the band-gap of the pristine polymer by using materials, which because of an alternating quinoid/aromatic structure, have a degenerate or nearly degenerate ground state. ${ }^{11}$ This approach is related to the use of alternating aromatic (phenylene or thiophene) and nonaromatic vinylene moities. Our approach incorporates conjugated donor-acceptor chromophores on a polymeric backbone. This strategy is partly based upon the known propensity of donor-acceptor pairs D-A to form charge transfer complexes, particularly when the donors are pyrrole derivatives and the acceptors are benzoquinones. ${ }^{12}$ Intermolecular charge-transfer complexes have been formed with quinone dopants and polypyrrole, ${ }^{13}$ while in the strong donor/acceptor limit, i. e., tetrathiafulvalene/tetracyanoquinodimethane(TTF/TCNQ) superconductive crystals are formed. ${ }^{14}$ We reasoned that the identical heterocyclic units of the Jenekhe polymers might be replaced by more easily prepared p-benzoquinone (quinoid) and heteroaromatic (pyrrole or thiophene) moieties in alternating fashion. A variation of this approach is to use the acceptor attached through an alkyl chain, as has been used in certain photoreaction center models. ${ }^{15}$ Because of synthetic imperatives, our strategy involved two sets of polymers. One involved preparation of polymers of type (D-A) through step-polymerization methods. The second set involved

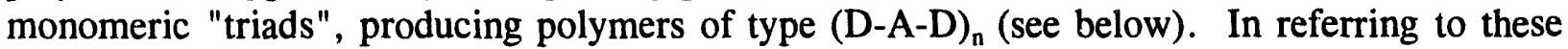
polymers, it is convenient to use acronyms which represent the polymer repeat unit, i. e., 
thiophene is $\mathbf{T}$, pyrrole is $\mathbf{N}$, benzoquinone is $\mathbf{Q}$, hydroquinone is $\mathbf{H}, \mathbf{p}$-phenylene is $\mathbf{P}$, and dimethoxybenzene (or dimethoxy-p-phenylene) is $\mathbf{D}$. Thus the polymer from bis(thienylpyrrole) is PTNT.

Our initial studies employed techniques which, although convenient preparatively, produced materials which were disordered with respect to attachment sites on the heteroaromatic ring. For instance, a pyrrole/quinone polymer, pNQ, was obtained by a condensation polymerization of pyrrole and benzoquinone, using precedented chemistry ${ }^{16}$ The resulting intrinsically semiconducting $\left(10^{-5} \mathrm{ohm}^{-1} \mathrm{~cm}^{-1}\right)$ black powder was improved in conductivity by two orders of magnitude upon protonic acid doping. ${ }^{17}$ A new approach was developed, based upon a directed synthesis, and provided an alternating copolymer with conductivities approaching $10^{3}$ $\mathrm{S} / \mathrm{cm} .^{18} \quad$ A related approach producing alternating thiophene and benzoquinone rings, $\mathrm{pTQ}$ was successfully reduced to practice through a transition-metal-catalyzed polymerization of a thiophenebis(magnesium chloride) and diiododimethoxybenzene followed by demethylation to pTH and oxidation. This material was significantly conductive $(\sigma=0.001 \mathrm{~S} / \mathrm{cm})$ and had an optical transition at $1.14 \mathrm{eV}$, indicative of a polaronic state. This approach holds promise for new syntheses of donor/acceptor polymers involving prior polymerization of a dimethoxybenzene followed by demethylation/oxidation, and has been utilized in at least one other case (see below).

\section{4. "Dimeric" and "Trimeric Monomers."}

The use of monomeric "diads" and "triads", e. g., terthiophene, as precursors to conducting polymers, presents several advantages and has been employed by a number of groups, ${ }^{19}$ including our own. First, the oxidation potential is reduced, reducing the overpotential required for efficient polymerization. Second, the disorder in the polymer is mimized, e. g., when 3-alkyl thiophene or pyrrole is polymerized, leading to head-to-head deconjugating steric interactions. Third, a greater variety of structure and substituent patter.ss in the resulting polymers can be achieved. Polymers of the (D-A-D) $n$ type took advantage of palladiumcatalyzed coupling of thiophene and dimethoxybenzene via their Grignard and iodide derivatives to yield 1,4-bis(thienyl)-2,5-dimethoxybenzene TDT. This "trimer" underwent smooth electropolymerization to produce films with high conductivities $(\sigma=32 \mathrm{~S} / \mathrm{cm})$. In an attempt to achieve more soluble polymers, Reynolds has produced the analogous n-alkyl ethers which have similar conductivities ${ }_{\star}^{20}$ Curiously, compensation of our methoxy $\mathrm{r}$ olymer with hydrazine

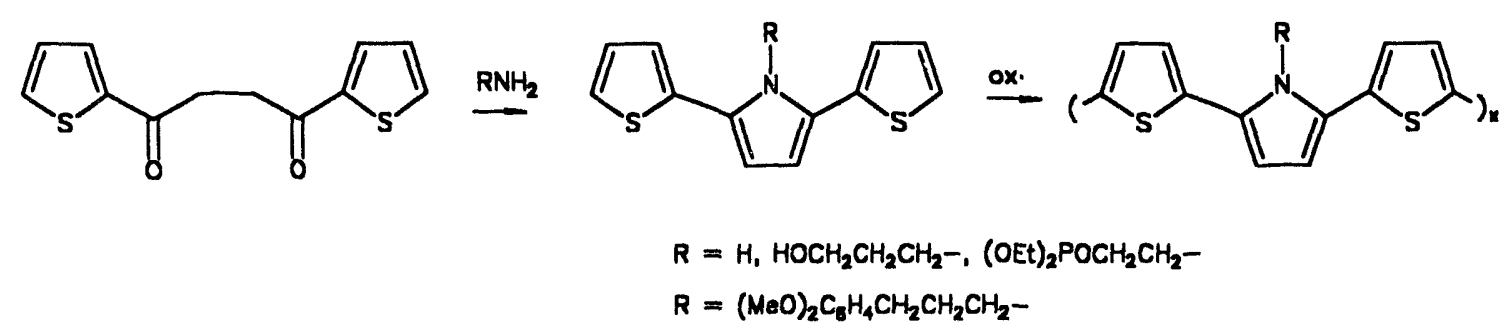

Figure 8. Synthesis of pTNT polymers. 
produced an orange polymer which was soluble in $\mathrm{N}$-methylpyrrolidone and which could be used to cast films. The polymer could be demethylated with $\mathrm{BBr}_{3}$ or pyridine $\mathrm{HCl}$ to yield the hydroquinone pTHT, which was readily oxidized to the desired quinone pTQT.

Polymers of the type (D$\left.D^{\prime}-D\right)_{n}$, in which the central ring was pyrrole, were readily obtained from the monomers produced through reaction of $1,4-$ bis(thiophene)butane-1,4-dione ${ }^{21}$ with an amine to produce 2,5bis(2-thiophene)pyrrole TNT using the approach developed by Wynberg ${ }^{22}$ and exploited further by Ferraris ${ }^{23}$ (see Figure 7). More recently, a more elegant and efficient approach ${ }^{24}$ was developed
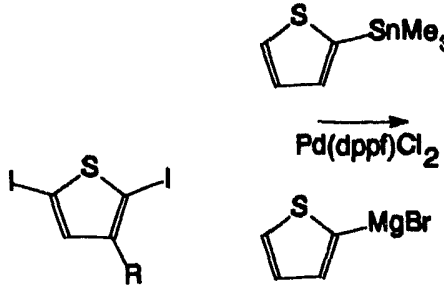<smiles>[R18]Cc1cccs1</smiles>

$\overrightarrow{\mathrm{Pd}(\mathrm{dppf}) \mathrm{Cl}_{2}}$

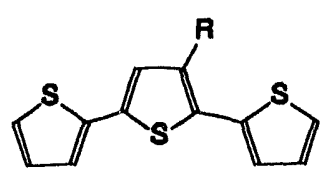

Figure 9. Synthesis of pTTT polymers. to alkylate the nitrogen atom in TNT with bromoalkanes. Reaction of TNT with 1.5-2 fold excess of bromoalkane in a DMSO/KOH system yielded $\mathrm{N}$-alkyl TNT derivatives. The method has been successfully used to prepare N- $\omega$-bromoalkyl TNT's, used in turn to produce variety of previously unknown functionalised TNT derivatives, including thiols, silanes, and phosphonates which can be covalently attached to a variety of surfaces for investigation of nanolithography (see Proposed Research). Produced in this way were over 12 triads and polymers (see Table I).

Polymers of the type (D-D'-D) in which D is thiophene and D' is a 3-alkyl-substituted thiophene have been prepared by Stille coupling ${ }^{25}$ of the requisite 2,5-diodothiophene (see Table II). An advantage of this class is that, unlike $\mathrm{N}$-substitution of pyrrole, 3-substitution of thiophene does not lead to deplanarization and its consequent increase in band gap and decrease in conductivity. Among the pendant groups attached are the self-doping benzoquinone groups, as well as the same alkanethiols, alkanesiloxanes, and alkanephosphonates used in the TNT monomers.

Our initial exploits into the use of covalently attached trimers have borne fruit. A number of "trimer" thiophenepyrrolethiophene monomers have been synthesized which allow incorporation of functionality at an $\mathrm{N}$ alkyl group and which form semiconducting films upon electropolymerization. When the $\mathrm{N}$-alkyl group is an alkanethiol, the resulting monomers attach strongly to gold or platinum surfaces and allow electropolymerization on the surface rather

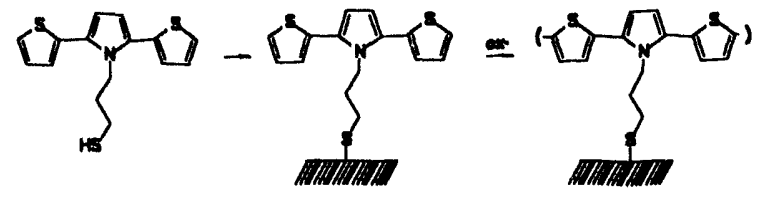

Figure 10. Attachment of TPT-C.SH to Pt surface. 
than precipitation after polymerization (see Figure 10). Such polymerized films exhibit remarkable adherence to the metal surface, in contrast to unsubstituted monomers, ${ }^{26}$ and form the basis for our proposed research in nanolithography. However, the requirement for generating the correct translational symmetry have led us to investigate the diad approach as well (see below).

Part of our effort in developing a variety of functional groups for ionic or covalent attachment to surfaces has led to the synthesis of a variety of structures in which a diethyl alkanephosphonate $\left(\mathrm{C}_{2}\right.$ or $\left.\mathrm{C}_{11}\right)$ is attached to a monomeric or trimeric thiophene at $\mathrm{C}-3$. The monocyclic thiophenes can be electropolymerized, or more prudently, copolymerized through Stille chemistry with nonalkylated thiophenes, leading to polymers with a pendant group on alternant thiophenes. Hydrolysis of the phosphonate before or after polymerization leads to a self-compensating, water-soluble polymer which is analogous to Wudl's poly(thiophenealkanesulfonate) ${ }^{27}$ Although space does not permit us to elaborate on the properties of every compound, particularly remarkable are our results for the polymer resulting from copolymerization of 2,5-(bistrimethylstannyl)thiophene with diethyl 11-[2,5-diodothiophene3]-undecylphosphonate (see Figure 11). This polymer was soluble in most organic solvents. Films cast from these solutions on the glass substrate were crimson in their reduced state $\left(\lambda_{\max }=527 \mathrm{~nm}\right)$, remarkably close to structurally homogeneous poly(3-dodecylthiophene) by McCullough and cited by him as evidence for extended conjugation. ${ }^{28}$ For improved polymer geometry we have also synthesized the asymmetric monomers diethyl 11-[5-trimethylstannyl-2iodothiophene-3]-undecylphosphonates for producing pure "head-to-tail" polymer through palladium-mediated homopolymerization. Cyclic voltammetry of the copolymer film deposited on a Pt electrode in acetonitrile solution containing $\mathrm{Et}_{4} \mathrm{NBF}_{4}$ electrolyte showed reversible waves $\mathrm{E}_{\mathrm{ox}}=1.01 \mathrm{~V}, \mathrm{E}_{\mathrm{red}}=0.80 \mathrm{~V}$ (vs. AgI $/ \mathrm{Ag}$ ). Upon oxidation, absorptions at 762 and $>1100 \mathrm{~nm}$ suggested formation of charge carriers (polarons and bipolarons). The polymer film could be repeatedly cycled with no change of CV profile.

Dealkylation of the phosphonate groups with iodotrimethylsilane produced a base soluble polymer which could be purified by dialysis through membranes of MW ca. 2,000 and 10,000. The $\lambda_{\max }$ was $505 \mathrm{~nm}$, compared with $430 \mathrm{~nm}$ for the corresponding ethanephosphonate $500 \mathrm{~nm}$ for Ikenue's poly(3thiophenealkylsulfona tes). ${ }^{29}$ The excellent processing and redox properties of this polymer suggest applications in optical switching. The kinetics of the redox cyc!icing, which should be improved for self-compensated polymers, will be further investigated.

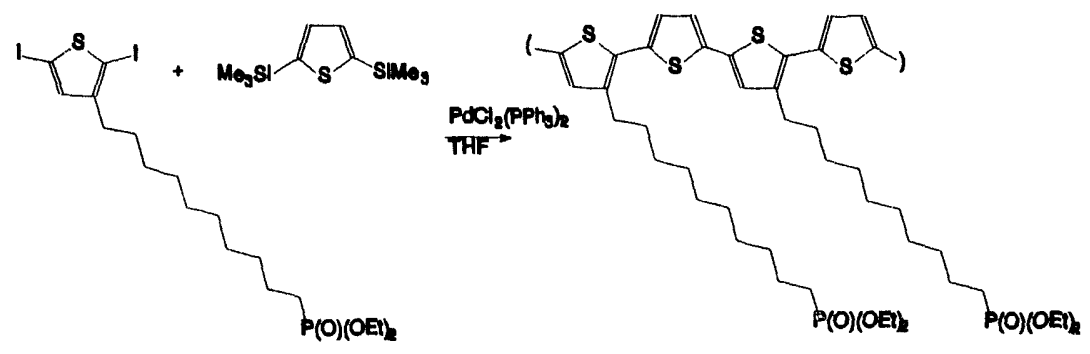

Figure 11. Synthesis of 3'alkylphosphonateTT. 
Table I. N-Alkyl-TNT monomers.

Table II 3'Alkyl TTT monomers.

\begin{tabular}{|c|c|c|c|}
\hline $\mathbf{R}$ & m. p. & $\mathbf{R}$ & m. p. \\
\hline $\begin{array}{l}\mathrm{n}-\mathrm{C}_{12} \mathrm{H}_{25} \\
\mathrm{n}-\mathrm{C}_{3} \mathrm{H}_{6} \mathrm{OH} \\
\mathrm{n}-\mathrm{C}_{3} \mathrm{H}_{6} \mathrm{SH} \\
\mathrm{n}-\mathrm{C}_{11} \mathrm{H}_{22} \mathrm{SH} \\
\mathrm{n}-\mathrm{C}_{3} \mathrm{H}_{6} \mathrm{C}_{6} \mathrm{H}_{4}(\mathrm{OMe})_{2} \\
\mathrm{n}-\mathrm{C}_{3} \mathrm{H}_{6} \mathrm{C}_{6} \mathrm{H}_{4}(\mathrm{OAc})_{2} \\
\mathrm{n}-\mathrm{C}_{3} \mathrm{H}_{6} \mathrm{C}_{6} \mathrm{H}_{4}(\mathrm{OH})_{2} \\
\mathrm{n}-\mathrm{C}_{4} \mathrm{H}_{8} \mathrm{C}_{6} \mathrm{H}_{4}(=\mathrm{O})_{2} \\
\mathrm{n}-\mathrm{C}_{2} \mathrm{H}_{4} \mathrm{P}(\mathrm{O})(\mathrm{OEt})_{2}\end{array}$ & $\begin{array}{l}\text { oil } \\
\text { oil } \\
\text { oil } \\
72-74^{\circ} \mathrm{C} \\
\text { oil } \\
--- \\
77-79^{\circ} \mathrm{C} \\
\text { oil }\end{array}$ & $\begin{array}{l}\mathrm{H} \\
\mathrm{n}-\mathrm{C}_{3} \mathrm{H}_{7} \\
\mathrm{n}-\mathrm{C}_{12} \mathrm{H}_{25} \\
\mathrm{n}-\mathrm{C}_{3} \mathrm{H}_{6} \mathrm{OH} \\
\mathrm{n}-\mathrm{C}_{3} \mathrm{H}_{6} \mathrm{SH} \\
\mathrm{n}-\mathrm{C}_{11} \mathrm{H}_{22} \mathrm{SH} \\
\mathrm{n}-\mathrm{C}_{3} \mathrm{H}_{6} \mathrm{Si}(\mathrm{OMe})_{3} \\
\mathrm{n}-\mathrm{C}_{3} \mathrm{H}_{6} \mathrm{C}_{6} \mathrm{H}_{4}(\mathrm{OMe})_{2} \\
\mathrm{n}-\mathrm{C}_{3} \mathrm{H}_{6} \mathrm{C}_{6} \mathrm{H}_{4}(\mathrm{OH})_{2} \\
\mathrm{n}-\mathrm{C}_{3} \mathrm{H}_{6} \mathrm{C}_{6} \mathrm{H}_{4}(=\mathrm{O})_{2} \\
\mathrm{n}-\mathrm{C}_{3} \mathrm{H}_{6} \mathrm{P}(\mathrm{O})(\mathrm{OEt})_{2} \\
\mathrm{n}-\mathrm{C}_{3} \mathrm{H}_{6} \mathrm{SO} \mathrm{O}_{3} \mathrm{Me}\end{array}$ & $\begin{array}{l}78-80^{\circ} \mathrm{C} \\
\text { oil } \\
45-47^{\circ} \mathrm{C} \\
\text { oil } \\
\text { oil } \\
\text { oil } \\
\text { oil } \\
\text { oil } \\
100-101^{\circ} \mathrm{C} \\
\text { oil } \\
\text { oil } \\
85-87^{\circ} \mathrm{C}\end{array}$ \\
\hline
\end{tabular}

\section{Electrically Conductive Polymeric Interconnects}

We have sought new strategies for patterning surfaces with electrically conductive polymeric materials. Previous work in our laboratories, as well as others, has demonstrated that polymeric films can be readily prepared electrochemically on conductive surfaces. Electrochemical deposition directly onto dielectric materials has not been feasible. This shortcoming has limited the technological utility of electrochemically produced conductive polymer films. We have recently developed a novel approach for electrochemically covering the surface of an insulator. Exploiting directional control of the electropolymerization, we have prepared submicron sizeci conducting polymer "wires" interconnecting Au islands. With this technique, we have grown poly(3-methylthiophene) and pTPTC ${ }_{11} \mathbf{S H}$ interconnections to $\mathrm{Au}$ microcrystal islands on mica substrate.

$\mathrm{Au}$ island films were made by thermally evaporating $\mathrm{Au}$ onto heated mica substrates. A SEM image of the Au island film is shown in Figure12. Most of the islands are of the size of $2-5 \mu \mathrm{m}$; many are microcrystalline with the (111) surface normal to the substrate. The separation between the islands ranges from ca. $0.2 \mu \mathrm{m}$ to $1.5 \mu \mathrm{m}$. Two separate Au electrodes on the island films were made by vacuum evaporation and were used as working electrodes 1 and 2, denoted as $\mathrm{WE}_{1}$ and $\mathrm{WE}_{2}$, respectively. $\mathrm{A} \mathrm{AgI/Ag}$ wire was used as the reference electrode and a Pt counter electrode was separated from the cell using a vycor frit and placed close to $\mathrm{WE}_{2}$. 
When this $\mathrm{Au}$ island film assembly was placed in an acetonitrile solution of either monomer and the potential of both working electrodes poised positively of the formal potential for oxidation of the monomer, films of doped polymer were deposited onto the surface of each electrode. $\mathrm{Au}$ islands which were in electrical contact with the working electrodes became coated as well whereas $\mathrm{Au}$ islands which were not in electrical contact remained uncoated. Figure 13 depicts the AFM image of two adjacent islands which display markedly different surface topology. The "marbled" surface is the island covered with doped polymer whereas the "smooth" surface is the electrically isolated island. In this configuration, directional growth of the polymer is vertical, towards the counter electrode. However, the directional growth of polymer is dramatically altered when the potential of $\mathrm{WE}_{2}$ is poised negative of $\mathrm{WE}_{1}$ (with a bipotentiostat). For example, when $\mathrm{WE}_{1}=1.2$ $\mathrm{V}$ and $\mathrm{WE}_{2}=-0.5 \mathrm{~V}$ electropolymerization proceeds horizontally across the surface much more rapidly than vertically. The rate of horizontal polymerization is proportional to the potential difference between $W E_{1}$ and $\mathrm{WE}_{2}$ and inversely proportional to the spacing between the islands. SEM and AFM analysis of the polymer coated $\mathrm{Au}$ island film sample revealed a thick polymer film on the surface of $\mathrm{WE}_{1}$ and on

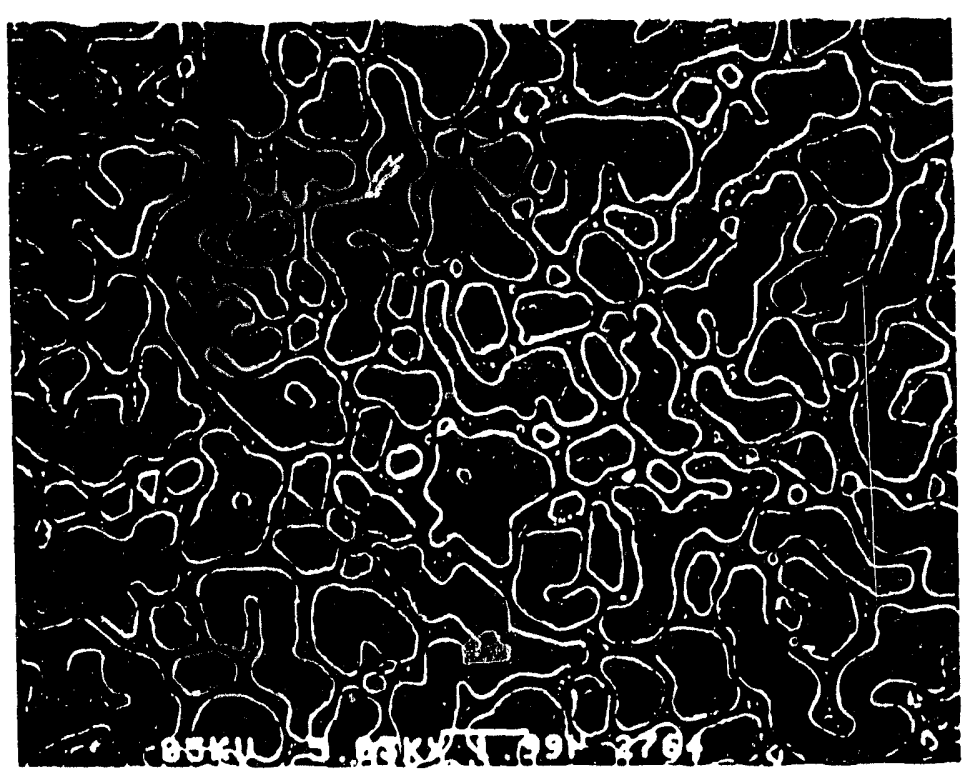

Figure 12. Scanning electron micrograph of $\mathrm{Au}$ island film.

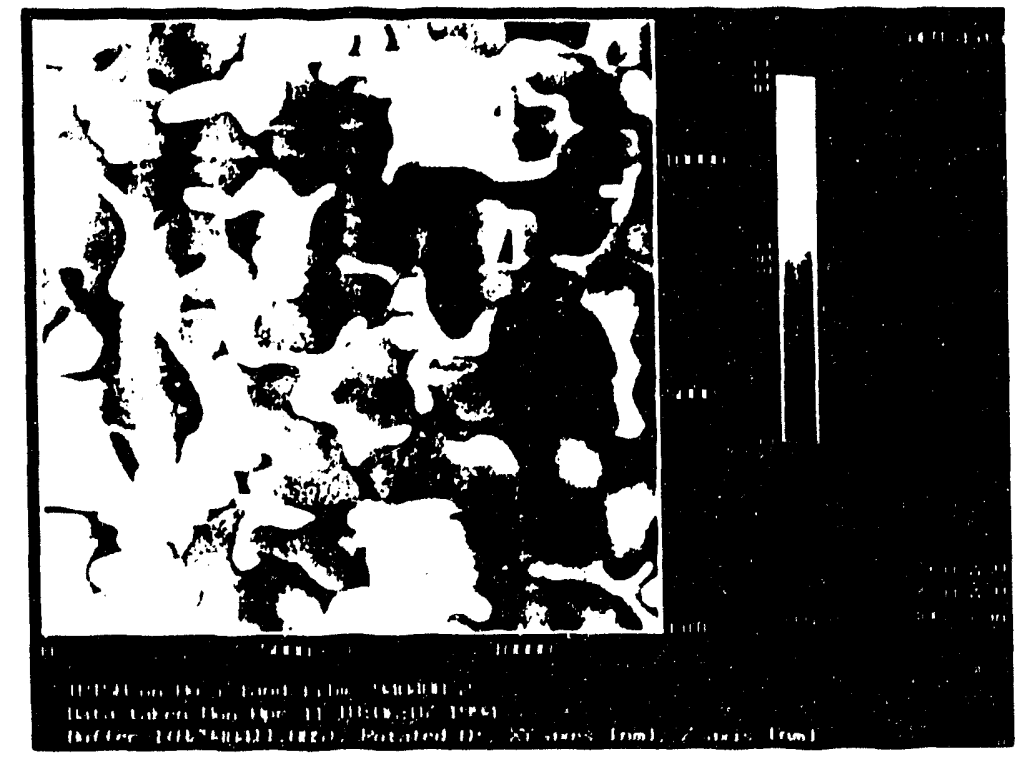

Figure 13. AFM micrograph of polymeric network interconnects between $\mathrm{Au}$ islands. 
sample revealed a thick polymer film on the surface of $\mathrm{WE}_{1}$ and on adjacent $\mathrm{Au}$ islands. No polymer was observed on the surface of $\mathrm{WE}_{2}$. In regions in between, polymer grew in the voids between the electrically isolated $\mathrm{Au}$ islands with little accumulation on their surfaces. Conductivity measurements confirmed that the polymeric networks, when doped, serve as submicron-sized polymer wire interconnections between isolated $\mathrm{Au}$ islands. Cross sectional analy $i$ of the AFM micrographs revealed that the polymer not only fills voids between the $\mathrm{Au}$ islands but also extends well above the surface of the adjacent islands.

One of the goals of this research program is the development of molecular level electronics devices based on conducting polymers. We have taken the first step by preparing polymeric interconnects between $\mathrm{Au}$ islands. The distinguishing feature of the polymer 'wires' is their size. We have succeeded in preparing polymer interconnects as thin as 200 $\mathrm{nm}$ employing a unconventional, nonlithographic technique. The feature size limitation in our experiment is the distance between the $\mathrm{Au}$ islands. A patterned substrate with reduced distances between the metal islands features may give rise to smaller conducting polymer features. The preparation of such a substrate is underway. Polymeric interconnects with reduced dimensions are expected to display anisotropic properties due to the preferred orientation of polymer molecules and may have important applications in electronics.

\section{References.}

1. (a) Su, W. P.; Schrieffer, J. R.; Heeger, A. J. Phys. Rev. Lett. 1979, 42, 1698; (b) Heeger, A. J.; Kivelson, S.; Schrieffer, J. R.; Su, W. P. Rev. Mod. Phys. 1988, 60. 781.

2. (a) Rice, M. J. Phys. Lett. A 1979, 71, 152. (b) Su, W. P.; Schrieffer, J. R.; Heeger, A., J. Phys Rev. B, 1981, 22, 2099.

3. For a review, see L. M. Tolbert, "Solitons in a Box. The Organic Chemistry of Electrically Conductive Polyenes," Accs. Chem. Res., 1992, 25, 561.

4. (a) J. L. Brédas, R. Silbey, D. S. Boudreaux, R. R. Chance, J. Am. Chem. Soc. 1983, 105, 6555. (b) H. E. Schaffer, R. R. Chance, K. Knoll, R. R. Schrock, and R. Silbey in Conjugated Polymeric Materials: Opportunities in Electronics, Optoelectronics and Molecular Electronics, J. L. Brédas and R. R. Chance, eds., Kluwer Academic Publishers, Boston, 1990, p. 365. (c) Guay, J.; Kasai, P.; Diaz, A.; Wu, R.; Tour, J. M.; Dao, L. H. Chem. Mater. 1992, 4, 1097.(d) Bally, T.; Roth, K.; Tang, W.; Schrock, R. R.; Knoll, K.; Park, L. Y. J. Am. Chem. Soc., 1992, 114, 2440.

5. L. M. Tolbert and M. E. Ogle, Synth. Metals, 1991, 41-43, 1389.

6. L. M. Tolbert, M. E. Ogle, Mol. Cryst. Liq. Cryst. 1990, 189, 279. (b) L. M. Tolbert, M. E. Ogle, J. Am. Chem. Soc., 1990, 112, 9519. (c) L. M. Tolbert, M. E. Ogle, J. Am. Chem. Soc., 1989, 111, 5958. 
7. (a) S. R. Marder, J. W. Perry, B. G. Tiemann, C. B. Gorman, S. Gilmour, S. L. Biddle, and G. Bourhill, J. Am. Chem. Soc. 1993, 2524. (b) S. R. Marder, C. B. Gorman, B. G. Tiemann, and L.-T. Cheng J. Am. Chem. Soc. 1993, 3007.

8. (a) J. A. Potenza, L. Zyontz, and W. Borowski, Acta. Cryst, B34 (1978) 193, (b) S. Kulpe, r.-J. Kuban, B. Schulz, and S. Dähne, Cryst. Res. Technol., 22 (1987). (b) K. Sieber, L. Kutschabsky, and S. Kulpe, Kristall u. Technik 9 (1974) 1111. (d) V. B. Zimer and S. Kulpe, J. Prakt. Chem., 317 (1975) 185.

9. (a) Kuhis, C. Synth. Metals, 1991, 43, 3681. (b) Kuhn, Christoph Phys. Rev. B, 1989, 40, 7776. (c) Reimers, J. R.; Craw, J. S.; Hush, N. S. Proceedings, U. S. Engineering Foundation Conf. on Molecular Electronics: Science and Technology, St. Thomas, U. S. V. I., 1991. (d) J. S. Craw, J. R. Reimers, G. B. Bacskay, A. T. Wong, and N. S. Hush, Chem. Phys., 1993, 176, 407-20. (e) Reimers, J. R.; Craw, J. S.; Wong, A.; Bacskay, G. B.; Hush, N. S. Mol. Cryst. Liq. Cryst. Sci. Technol., 1993, Seci. is, 234, 51 .

10. L. M. Tolbert, and Xiaodong Zhao, Synth. Metals, 1993, 55-57, 4788.

11. (a) S. A. Jenekhe, Nature, 1986, 322, 348. (b) M. Kobayashi, N. Colaneri, M. Boysel, F. Wudl, and A. J. Heeger, J. Phys Chem., 1985, 82, 5717. (c) F. Wudl, M. Kobayashi, N. Colaneri, M. Boysel, A. J. Heeger, Mol. Cryst. Liq. Cryst. 1985118 , 199. (d) M. Kertesz and Y. S. Lee, J. Phys. Chem., 1987, 91, 2690. (e) J. L. Brédas, Mol. Cryst. Liq. Cryst. 1985, 118, 49.

12. (a) K. Maruyama, T. Otsuki, H. Tamiaki, Bull. Soc. Chem. (Japan) 1985, 58, 3049.

(b) Z. Yoshida, T. Kobayashi, Tetrahedron, 1970, 26, 267.

13. B. Zinger, Synth. Metals, 1989, 30, 209.

14. D. O. Cowan and F. M. Wiygul, Chem. Eng. News, 1986, 64, 28.

15. J. Weiser, H. Staab, Angew. Chem. 1984, 96, 602.

16. (a) H. Fischer, A. Treibs, and E. Zaucker, Chem. Ber, 1958, 92, 2026. (b) E. Buliock, Can J. Chem. 1958, 36, 1744. (c) R. Möhlau and A. Redlich, Ibid., 1966, 44, 3605. (d) P. Kuser, E. F. Frauenfelder, and C. H. Eugster, Helv. Chim. Acta, 1971, 54, 969.

17. J. W. Kowalik, L. M. Tolbert, Synthetic Met., 1991, 41, 435.

18. L. M. Tolbert and J. W. Kowalik, Abstracts, National Meeting, American Chemical Society, Atlanta, April 1991.

19. (a) Guay, J.; Diaz, A.; Wu, Ruilian, Tour, J. M. J.Am. Chem. Soc. 1993, 115, 1869. 
20. J. P. Ruiz, A. D. Child, K. N. Yak, D. S. Marynick, J. R. Reynolds, Abstracts, Xth International Conference on Science and Technology of Synthetic Metals, Tübingen, July 1990.

21. Stetter,H. and Rajh,B.,Chem.Ber.,(1976) 109534.

22. H. Wynberg, J. Metselaar, Synth. Commun. 1984, 14, 1.

23. J. P. Ferraris, T. R. Hanlon, Polymer, 1989, 스, 1319.

24. H. Heaney, and S. V. Ley, J.Chem.Soc.Perkin Trans I, 1973, 499.

25. (a) J. K. Stille, Angew. Chem., Int. Ed. Engl., 198625 50. (b) A. M. Echavarren, and J. K. Stille, J. Am. Chem. Soc., 1987109 5478. (c) T. R. Bailey, Tetrahedron Lett., 1986 4407. (d) S. Gronowitz, and D. Peters, Heterocycles, $1990 \underline{30} 645$.

26. J. Kowalik, L. M. Tolbert, L. A. Bottomley, Y. Ding, K. Vogt, and P. Kohl, Synthetic Metals, 1993, 55, 1171.

27. Patil, A. O., Ikenoue, Y., Colaneri, N., Chen, J., Wudl, F. and Heeger, A. J., Synth. Met., (1987) 20 151. Ikenoue, Y., Chiang, J., Patil, A. O., Wudl, F. and Heeger, A. J., J. Am. Chem. Soc., (1988) 110 2983. Ikenoue, Y., Uotani, N., Patil, A. O., Wudl, F. and Heeger, A. J., Synth. Met., (1989) $\underline{30} 305$.

28. McCullough,R.D., Lowe,R.D., Jayaraman,M. and Anderson,D.L., J.Org.Chem.,(1993) 58904.

29. Ikenoue,Y., Tomozawa,H., Saida,Y., Kira,M. and Yashima,H.,Synth.Met.,(1991) 40 333. 
Publications and Presentations.

1. Publications, 1992-94 (DOE-supported publications marked with *):

Submitted or in press:

Laren M. Tolbert and Jeanne E. Haubrich, "Photoexcited Proton Transfer from Enhanced Fhotoacids,", J. Am. Chem. Soc. submitted.

Laren M. Tolbert, Xiao-Jing Sun, and E. C. Ashby, "A Photochemical Probe for Single Electron Transfer in Nucleophilic Aliphatic Substitution: Evidence for Geminate Radical Coupling in the Solvent Cage", J. Am. Chem. Soc., submitted.

Already published:

Laren M. Tolbert, Lilia C. Harvey, and Rachel C. Lum, "Excited-State Proton Transfer from Hydroxyalkyl Naphthols", J. Phys. Chem., 97, 13335 (1993).

*Janusz Kowalik, Laren M. Tolbert, Lawrence A. Bottomley, Youzhen Ding, Kirk Vogt, and Paul Kohl, "Strongly Adherent Conductive Heteropolymers", Synthetic Metals, 55, 1171 (1993)

*Laren M. Tolbert and Xiaodong Zhao, "Extended Cyanine Dyes", Synthetic Metals, 57, 4782 (1993).

Laren M. Tolbert, Susan M. Fitzwater, Narciso Raya, and Michael Stapleton, "Substituent Effects on Carbanion Photophysics. An Application of The Energy Gap Law," J. Phys. Chem. 96, 4492 (1992).

*Laren M. Tolbert, "Solitons in a Box. The Organic Chemistry of Electrically Conductive Polyenes," Accs. Chem. Res., 25(12), 561 (1992).

D. L. Tomasko, B. L. Knutson, C. A. Eckert, J. E. Haubrich, and L. M. Tolbert, "Fluorescence Investigation of Cosolvent/Solute Interactions in Supercritical Fluid Solutions, Am. Chem. Soc. Symp. Ser.488, 84 (1992).

2. Meetings and Symposia, 1992-94 (DOE-supported presentations marked with *):

*"Conducting Polymer Interconnects on Submicron Gold Island Films", Materials Research Society, Boston, MA December 1994

*"Submicron-sized Electrically Conducting Polymer Interconnects on Gold Island Films", Southeast Regional Meeting, American Chemical Society, November 1994. 
*"Electrochemical Nanoscale Patterning of Surfaces with Electrically Conductive Polymers", National Meeting, American Vacuum Society, Denver, CO October 24, 1994 [Invited].

*"A Poly(3-alkylthiophene-co-thiophene) with Improved Electronic and Processing Properties." Materials Research Society, Boston, MA December 1994

*"Optical Electron Transfer in Extended Cyanines", IUPAC Conference on Photochemistry, Prague, Czech Republic, July 1994.

*"Poly(3-alkylthiophene-co-thiophene)s with Enhanced Electronic Properties", Southwest Regional Meeting, American Chemical Society, Dallas, TX Octobert 1994 [Invited].

*"Extended Cyanine Dyes." International Conference on Science and Technology of Synthetic Metals, Gothenburg, Sweden, August 14, 1992.

*"Strongly Adherent Conductive Heteropolymers." International Conference on Science and Technology of Synthetic Metals, Gothenburg, Sweden, August 16, 1992.

"1-Allyl-2-naphthol. The Case Against Excited-state Proton Transfer." XXIV IUPAC Meeting on Photochemistry, Leuven, Belgium, July 20, 1992.

"Proton Transfer Dynamics in Strong and Weak Photoacids," Fourth Winter Conference, InterAmerican Photochemical Conference, Clearwater Beach Florida, January 4, 1992 [Invited].

\section{Current and Pending Support.}

Laren M. Tolbert:

National Science Foundation, "Charge Distribution in Photoexcited Molecules," CHE9111768, 6-1-91 to $11-1-94, \$ 333,000$.

Departinent of Energy, "The Organic Chemistry of Conducting Polymers," DE-FG0591ER45194, 7-1-91 to $12-31-94, \$ 358,670$.

National Aeronautics and Space Administration, "High-Performance Polymer and Ceramics Center", consortium with Clark Atlanta University, 1-1-92 to 9-30-96. total budget ca. $\$ 8.5 \mathrm{M}$, value to L. M. T. $\$ 80-100,000$ (\$20,000 annually).

Department of Energy, "The Organic Chemistry of Conducting Polymers," (This proposal) $\$ 390,000$. 
Lawrence A. Bottomley:

Athens Environmental Research Laboratory, "Demonstration and Evaluation of Chemical Remediation Technologies," (L.A.B. as Co-I.; F. M. Saunders, P.I.), January, 1994 through December, 1995, \$1.0 million (L.A.B.'s portion as yet undetermined)

Polymer Education and Research Center, Georgia Institute of Technology, "Molecular Scale Patterning of Electronically Conductive Polymer Films with Scanning Probe Microscopy", January, 1994 - December, 1994, \$ 7,000

National Science Foundation, "Traineeships in Environmental Physical and Mathematical Science and Engineering" (L.A.B. as Co-I.; R. F. Browner, P.I.), September, 1994 through August, 1999, $\$ 537,500$

Emory/Georgia Tech Biomedical Technology Research Center, "Molecular Design of Biomaterials for Tissue Regeneration: Substrate-Directed Activation of G Protein Receptors," (L.A.B. as Co-I., E. L. Chaikof and P.J. Ludovice, P.I.'s) July, 1994 June, 1995, $\$ 2,000$

Georgia Tech Biomedical Research Support Program, "Two- and Three-Dimensional Structures of DNA Complexes by Scanning Probe Microscopy and X-ray Crystallography", (with L. D. Williams), July, 1994 through June, 1995, \$4,000

National Science Foundation, "New Cathode Materials for the Electrochemical Synthesis of Sodium Hydrosulfite" (with P. Kohl and J. Winnick as Co-I.s) , August, 1994 through July, $1997, \$ 280,000$

Pending Support forLAB:

National Institutes of Health, "ATR-IRS/SPM Probe of Biological Interfaces" (L.A.B. as P.I., R. A. Dluhy, Co-P.I.), April, 1995 through March, 1997

National Science Foundation, "New Probes of Biomolecular Monolayer Struciure",(L. A. B. as Co-P.I. with R.A. Dluhy of UGA), December, 1995 through November, 1998, $\$ 452,370$

National Aeronautics and Space Administration, "Structures and Crystal Growth Mechanisms of Intercalated Drug-DNA Complexes", (with L. D. Williams), \$370,000

Department of Energy, "The Organic Chemistry of Conducting Polymers, (L.A.B. CoP.I. with L. M. Tolbert, P.I.), January, 1995 through December, 1997, \$ 390,000 (this proposal). 

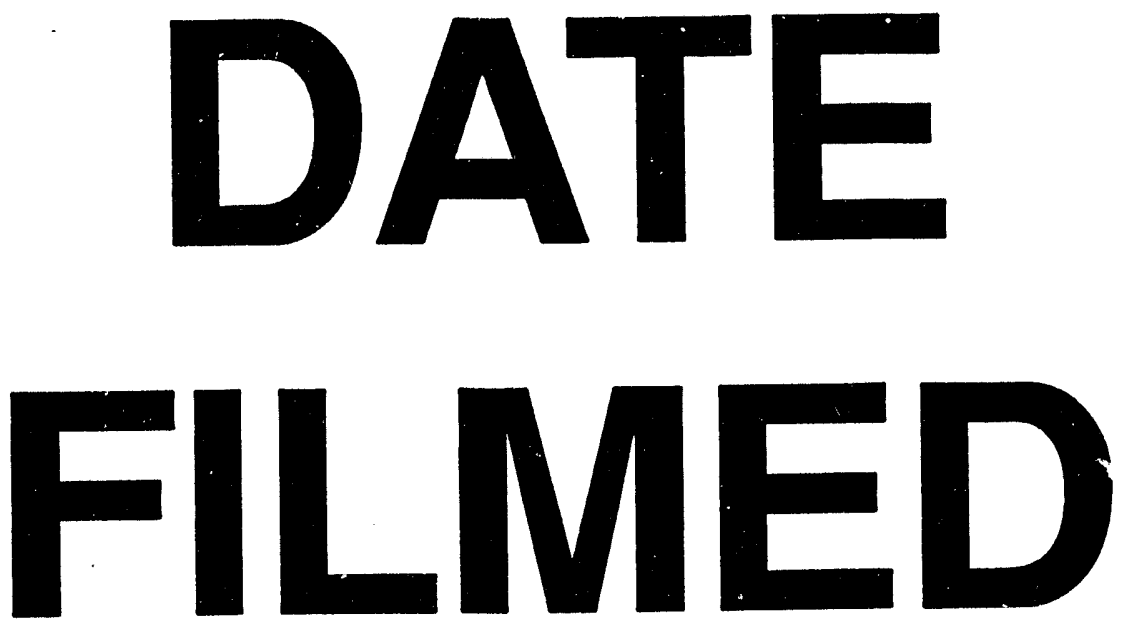

$10 / 4 / 94$
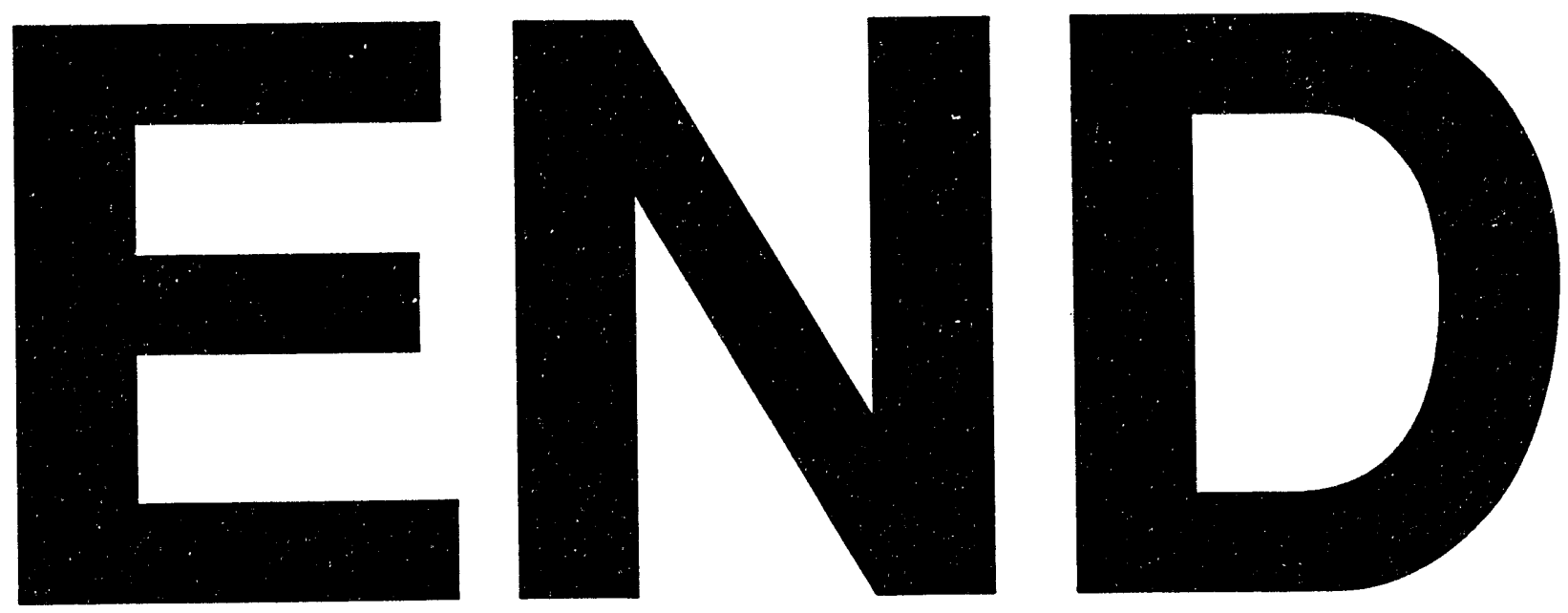
